\title{
Wandering behaviour of the mud-crab Helice tridens related to evasion of cannibalism
}

\author{
Yasushi Kurihara, Katsuhiro Sekimoto, Masahide Miyata
}

Biological Institute, Faculty of Science, Tohoku University, Sendai 980, Japan

\begin{abstract}
Burrowing and migration behaviour of the mud-crab Helice tridens (De Haan) were examined in relation to cannibalism using an experimental habitat simulating an estuarine area as well as under natural conditions in the field. In summer, when the population density was greater than the carrying capacity of the number of burrows in an experimental habitat, large individuals preyed upon emerged small ones and the number of smaller individuals decreased until total numbers approximated the carrying capacity of burrows in the experimental habitat. These results suggest that burrows provide protection from predation. In the field, large individuals ceased to burrow, and migrated to a brackishwater lagoon, while small individuals dug burrows, and became dispersed over all the reed marsh in summer. Habitat segregation due to migration of large individuals to the lagoon and dispersion of small ones in the reed marsh may lessen the chance of cannibalism.
\end{abstract}

\section{INTRODUCTION}

The commercial crab Cancer magister Dana inhabiting the west coast of North America has been reported to exhibit cannibalism frequently (Mackay 1942, Bulter 1954, Gotshall 1977, Stevens et al. 1982). In an estuary in Washington State, USA, about $20 \%$ of the gut contents of $C$. magister consisted of parts of the bodies of conspecifics, suggesting that their population size decreased by frequent cannibalism (Stevens et al. 1982). In a grapsid crab, Hemigrapsus penicillatus (De Haan), which inhabits inter-and infra-littoral boulder shores in the brackish estuary of Japan, it has been observed that small crabs after settling are preyed upon by large ones, and that the availability of narrow gaps between boulders and stones as shelter reduced cannibalism (Kurihara \& Okamoto 1987). These authors concluded that suitable shelter for small crabs is an important factor maintaining the stability of the $H$. penicillatus population.

Almost all crabs which inhabit intertidal sandy and muddy flats in brackish lagoons and estuaries are known to dig burrows and feed around each burrow (e. g. Fielder 1970, Yamaguchi 1970, Evans et al 1976, Wada 1985). It has also been observed that these crabs leave their burrows and move downshore to the waterlogged tidal flat, and feed there. This wandering behaviour is considered due to high population density and poor food or water supply in the burrowing area (e. g. Yamaguchi \& Tanaka 1974, Wada 1981, Murai et al. 1982, Henmi 1984).

The mud-crab Helice tridens (De Haan) is one of the most frequently seen grapsid crabs in the reed marshes around brackish lagoons and river mouths of northeastern Japan (Ono 1959, Takeda \& Kurihara 1987 a).

Although these crabs inhabit burrows in the reed marshes, many large individuals have frequently been seen in lagoons and creeks where no burrows are apparent. Nevertheless, their behaviour in the reed marsh and lagoon has not previously been described in detail with respect to seasonal changes in the number and the body size of wandering individuals.

In the present study, the relationship of burrowing and migration to cannibalism was examined in Helice tridens. Initially, in both the reed marsh and the lagoon under natural field conditions, size distributions and seasonal changes in the number of wandering individuals were investigated in relation to seasonal changes in numbers of individuals and burrows in the reed marsh habitat. Subsequently, seasonal changes in burrowing and wandering behaviour were examined using an experimental habitat simulating an estuary consisting of a 'brackish-water lagoon', 'tidal flat' and 'reed marsh'. In addition, the relationship of cannibalism to the number of emerged crabs was examined on the basis of changes in the population and burrow density in the experimental habitat. 


\section{MATERIALS AND METHODS}

\section{Field experiments}

Wandering behaviour in the lagoon and reed marsh. Investigations were conducted at a brackish water reed marsh adjoining a brackish water lagoon in the estuary of the Nanakita River, Miyagi Prefecture, Japan $\left(38^{\circ} 15^{\prime} \mathrm{N}, 141^{\circ} 01^{\prime} \mathrm{E}\right)$. The reed marsh, dominated by Phragmites australis (Trin.), is $35 \mathrm{~m}$ in width, rising at a slope of about $3^{\circ}$, and is exposed regularly at low tide.

Seasonal changes in size and number of crabs Helice tridens appearing in the lagoon next to the reed marsh were studied. A square vessel made of vinyl chloride $(25 \times 25 \times 37 \mathrm{~cm}$ height), in which crabs were retained, was buried with $1 \mathrm{~cm}$ of the upper part above the sediment surface in the lagoon $5 \mathrm{~m}$ distant from the reed marsh edge and left for $24 \mathrm{~h}$. H. tridens trapped in the vessel were counted and measured for carapace width on one day each month from May to October 1985.

To investigate seasonal changes in the wandering of crabs on the reed marsh, 3 vessels (each $25 \times 25 \times 37 \mathrm{~cm}$ height) were buried with their upper parts exposed to a height of $1 \mathrm{~cm}$ above the mud surface of the reed marsh, respectively 10,20 and $30 \mathrm{~m}$ distant from the seaward edge of the marsh. The $20 \mathrm{~m}$ station was $3 \mathrm{~cm}$ vertically higher than the $10 \mathrm{~m}$ station, and the $30 \mathrm{~m}$ station $17 \mathrm{~cm}$ higher than the $20 \mathrm{~m}$ station. Helice tridens crabs trapped in each vessel were counted and measured for carapace width. This experiment was performed one day each month from May to October 1985.

To examine the wandering behaviour of Helice tridens in the reed marsh in relation to tidal rise and fall, the following experiment was performed. Three vessels (each $25 \times 25 \times 37 \mathrm{~cm}$ height) were buried with their upper parts exposed at heights of 1,10 and $20 \mathrm{~cm}$ above the mud surface of the 10,20 and $30 \mathrm{~m}$ stations in the reed marsh. $H$. tridens individuals trapped in each vessel were collected at specified times according to phase of the tide and checked for number and carapace width. At the same time, changes in tidal height were recorded. The experiment was performed on 18 to 19 June, 29 to 30 August and 15 to 16 October 1985 .

Numbers of individuals and burrows in the reed marsh. To clarify seasonal changes in the distribution of individuals in the reed marsh, permanent quadrats $(50 \times 50 \mathrm{~cm})$ were marked off on the marsh at $5 \mathrm{~m}$ intervals starting at a point $5 \mathrm{~m}$ distant from the seaward edge of reed marsh toward the land, and the number of individuals in each quadrat, including those observed on the mud surface and those occupying and inhabiting burrows, were counted and measured from spring to fall of 1986 .

Seasonal changes in diameter and number of burrows in 4 quadrats, marked off on the red marsh randomly, were also investigated from spring to fall of 1983 and 1984.

\section{Laboratory experiments}

Experimental habitat. The experimental habitat used in this study is shown in Fig. 1. Sea sand was placed in a vessel made of fiberglass reinforced plastic
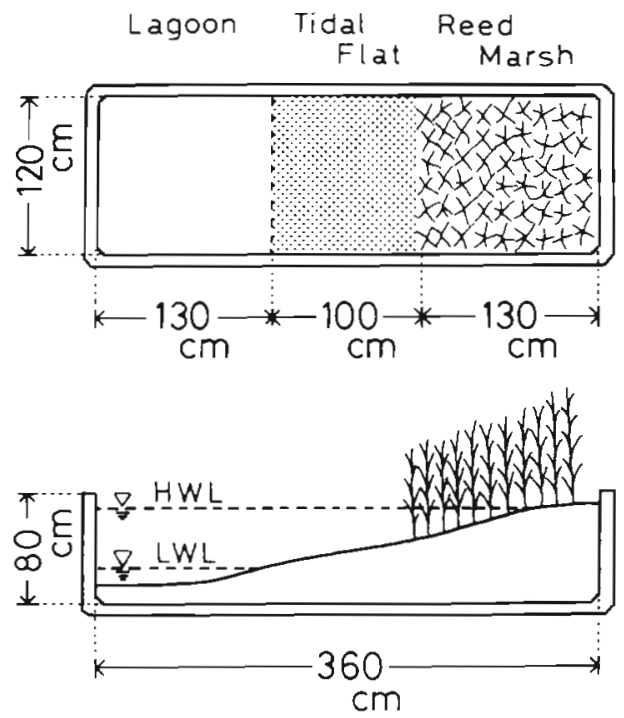

Fig. 1. Top and side views of the experimental habitat. The habitat consists of 3 plots including 'reed marsh', 'tidal flat' (exposed and submerged repeatedly) and 'lagoon' (constantly filled with water). HWL: high water level; LWL: low water level

to form a slope of about $4^{\circ}$, and the surface was covered to a thickness of $20 \mathrm{~cm}$ with mud collected from the reed marsh. Young shoots of the reed Phragmites australis (Trin.), collected in May, were transplanted to the upper $1 / 3$ of the mud area at almost the same density (160 stems $\mathrm{m}^{-2}$ ) as that on the reed marsh. The vessel was then filled with diluted artificial seawater $1.5 \%$ chlorinity) and the natural tidal rhythm was simulated by an automatic in/out flow produced by a pump and timer. Water levels at 'high and low tides' were set so that the reed-transplanted area and lowest $1 / 3$ of the muddy area would be submerged. The reeds grew to a height of $2 \mathrm{~m}$ in June. This experimental habitat consisted of 3 compartments: a reed-transplanted part (hereafter referred to as 'reed marsh') which was subjected to repeated exposure and submergence, a muddy part (hereafter referred to as 'tidal flat'), and a constantly submerged part (hereafter referred to as 'lagoon'). Several such experimental habitats were 
constructed in the botanical garden of our university located about $15 \mathrm{~km}$ distant from the estuary toward land, and placed in transparent vinyl housing so as not to be affected by wind or rain.

Burrowing behaviour in experimental habitats. Large $(2.5$ to $3.0 \mathrm{~cm}$ carapace width) and small individuals $(1.3$ to $1.8 \mathrm{~cm})$ of Helice tridens were transferred to the 2 experimental habitats separately and the imposed tidal rhythm was set to about $6 \mathrm{~h}$ 'flood' and $6 \mathrm{~h}$ 'ebb'. The number of individuals transferred to the experimental habitats was varied and those inhabiting burrows in the daytime at 'low tide' were counted. These crabs were considered to be burrow-building crabs, since the burrows crumbled during the submerged period but were repaired or dug again during the exposed period (Takeda \& Kurihara 1987b). This experiment for large crabs was performed from 15 August to 12 September and from 29 October to 20 November 1985, and for small crabs from 25 August to 13 September and from 16 October to 13 November 1985. Fish meal pellets (Kyorin Co. Ltd) were provided as food.

Habitat preference of wandering individuals in experimental habitats. To determine the habitat preference of wandering individuals on 'reed marsh', 'tidal flat' and 'lagoon' in summer, 2 large individuals (2.5 to $3.0 \mathrm{~cm}$ carapace width) were transferred to the experimental habitat at 'low tide' conditions, based on our preliminary field observation that at low tide in summer they wander about. On one day and night after transfer, the locations to which they had migrated were recorded at $30 \mathrm{~min}$ intervals from 14:00 to $23: 00 \mathrm{~h}$.

For small crabs, almost all individuals $(1.3$ to $1.8 \mathrm{~cm}$ carapace width) dug burrows in the 'reed marsh' during $24 \mathrm{~h}$ after transfer at a low population density. Wandering small individuals occurred at a high population density. Based on the observations as above, the locations of wandering small individuals at 'low tide' conditions were observed for various population sizes at $24 \mathrm{~h}$ after transfer.

Relationship between water level and number of wandering crabs in experimental habitat. To examine the relationship between the water level and wandering behaviour, 10 large ( 2.5 to $3.0 \mathrm{~cm}$ carapace with) and 10 small crabs ( 1.3 to $1.8 \mathrm{~cm}$ ) were put into 2 experimental habitats separately, and the number of individuals leaving their burrows was recorded each hour during both the day and night in relation to the water level. This experiment was conducted 5 times during the period from 26 September to 5 October 1986.

Cannibalism in experimental habitat. To determine the occurrence of cannibalism among individuals of different size, large $(2.5$ to $3.0 \mathrm{~cm}$ carapace width), middle-size $(2.0$ to $2.5 \mathrm{~cm})$ and small crabs $(1.0$ to $2.0 \mathrm{~cm}$ ) were mixed at a ratio of $1: 1: 4$, based on prelimi- nary field observations. They were transferred to 3 experimental habitats in total numbers of 48,36 and 30 . The tidal rhythm of each habitat was set at $6 \mathrm{~h}$ 'flood' and $6 \mathrm{~h}$ 'ebb' and the numbers of survivors of each size crab were counted after about 1 mo. This experiment was carried out in the spring, summer and fall of 1986.

\section{RESULTS}

\section{Field experiments}

\section{Wandering individuals in lagoon and reed marsh}

The number of crabs trapped in vessels placed in the lagoon water was low in May but increased through June and July, reaching a maximum in August (Fig. 2). Numbers decreased in September and were lowest in October.

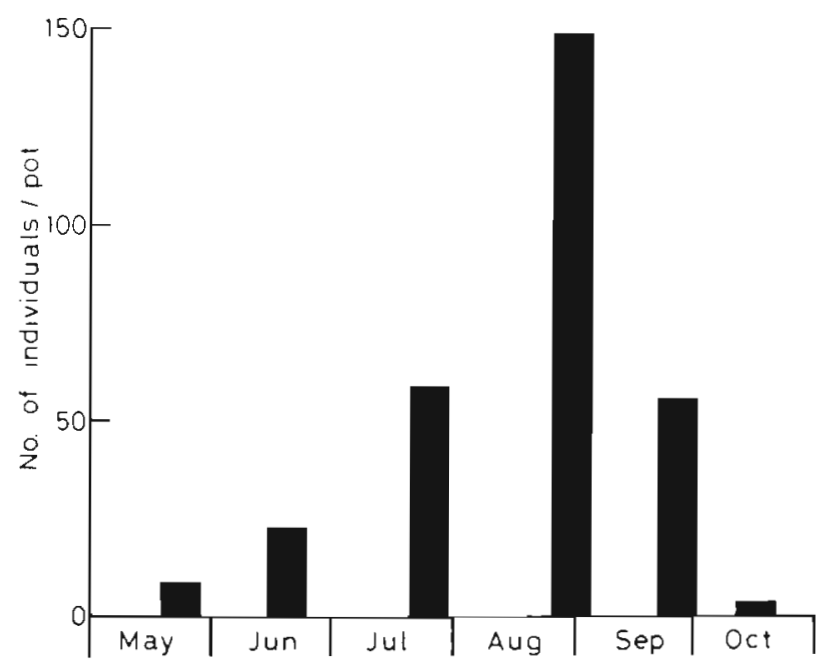

Fig. 2. Helice tridens. Seasonal changes in the number of crabs trapped in a square vessel $(25 \times 25 \times 37 \mathrm{~cm}$ height $)$ placed on the bottom mud of the lagoon $5 \mathrm{~m}$ from the reed marsh edge

In August, crabs of carapace width $<2 \mathrm{~cm}$ made up only $8.1 \%$ of the captured population (Fig. 3). Almost all individuals trapped were $>2 \mathrm{~cm}$ throughout observation periods. Crabs with carapace width $>2 \mathrm{~cm}$ are hereafter referred to as 'large individuals' and with width $<2 \mathrm{~cm}$, as 'small individuals'.

Among crabs trapped in vessels placed at the $10 \mathrm{~m}$, $20 \mathrm{~m}$ and $30 \mathrm{~m}$ stations on the reed marsh, those with carapace width $>2 \mathrm{~cm}$ were predominant (Table 1). However, the rate of capture of small crabs was greater in the reed marsh $(35.2 \%$ on average) than in the lagoon (8.1\%) in August. The number of crabs in the $30 \mathrm{~m}$ station was less than those in either the $10 \mathrm{~m}$ or $20 \mathrm{~m}$ station, except in late August. This may possibly 


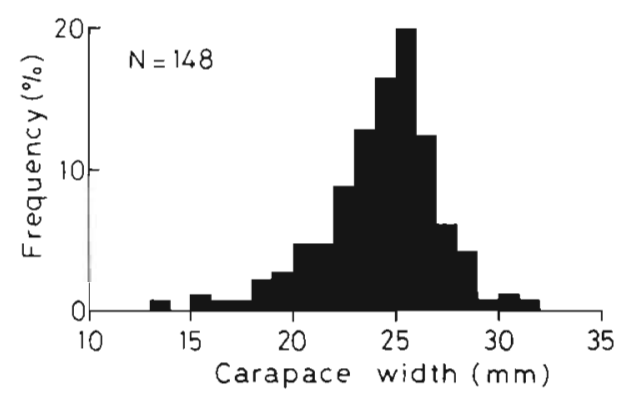

Fig. 3. Helice tridens. Frequency distribution of carapace width of crabs trapped in a square vessel $(25 \times 25 \times 37 \mathrm{~cm}$ height) placed on the bottom mud of the lagoon $5 \mathrm{~m}$ from the reed marsh edge

be related to the lower frequency of submergence at the $30 \mathrm{~m}$ station than at the other 2 stations.

Relationship between number of wandering individuals in the reed marsh and tidal rhythm

No crabs were found in vessels protruding 10 or $20 \mathrm{~cm}$ above the mud surface, although these vessels were submerged at high tide. Crabs were however caught in vessels projecting $1 \mathrm{~cm}$ above the sediment surface (Fig. 4), indicating that crabs migrate by walking on the mud surface even during submerged periods, and not by swimming.

In June (Fig. 4a), the number of trapped individuals was high at full high tide and low at low tidal levels. The number trapped at the $30 \mathrm{~m}$ station was quite low; this station was always exposed. It is thus evident that Helice tridens leave their burrows to wander over a wide area by walking when the reed marsh is submerged by the tide. In August (Fig. 4b), no correlation could be found between tidal level and number of trapped individuals. That is, their number was high at ebb tide following submergence, showing that in summer, large $H$. tridens individuals wander for a long time during and after submergence. With temperature decreases in October (Fig. 4c), the number of $H$. tridens individuals wandering outside their burrows was again high only during submerged periods.

Seasonal changes in the density of large and small burrows in the reed marsh

Seasonal changes in the density of large diameter burrows $(>2.5 \mathrm{~cm})$ and smal diameter burrows $(<2.5 \mathrm{~cm})$ in the reed marsh are given in Fig. 5. The critical diameter was taken as $2.5 \mathrm{~cm}$ because large individuals with carapace width $>2 \mathrm{~cm}$ had been reported to dig and occupy burrows $>2.5 \mathrm{~cm}$ in diameter (Takeda \& Kurihara 1987a). The density of large burrows was remarkably lower during August and September than during other months, in both of the 2 yr of observation. This reduction in the number of large burrows in summer may have been due to migration of large individuals from the reed marsh to the lagoon or it may be that they simply stop burrowing during summer. A number of small burrows were observed throughout the experiment and there were always more small burrows than large ones.

Seasonal changes in the distribution of individuals in the reed marsh

In mid-April, both large and small crabs were concentrated on the higher ground of the reed marsh far from the lagoon, where they overwintered in the burrows (Fig. 6). In June, large individuals became dispersed all over the reed marsh but small ones migrated toward the lagoon, giving rise to a peak occurrence at the water's edge. Hardly any large individuals could be found in late July. Small individuals became dispersed all over the marsh during this period but their number decreased subsequently. No large individuals were observed in late August, but small ones maintained essentially the same distribution pattern as that in late July. In October and November,

Table 1 Helice tridens. Number of individuals trapped in square vessels placed in the reed marsh

\begin{tabular}{|c|c|c|c|c|c|c|c|}
\hline \multirow[t]{2}{*}{ Station } & \multirow[t]{2}{*}{ Size $^{a}$} & \multicolumn{6}{|c|}{ Number of individuals per pot per day } \\
\hline & & 23-24 May & 18-19 Jun & $25-26 \mathrm{Jul}$ & 29-30 Aug & $26-27 \mathrm{Sep}$ & $15-16$ Oct \\
\hline \multirow[t]{2}{*}{$10 \mathrm{~m}$} & Large & 3 & 24 & 23 & 64 & 9 & 10 \\
\hline & Small & 0 & 7 & 3 & 33 & 1 & 5 \\
\hline \multirow[t]{2}{*}{$20 \mathrm{~m}$} & Large & 2 & 33 & 17 & 39 & 13 & 17 \\
\hline & Small & 0 & 0 & 9 & 31 & 0 & 9 \\
\hline \multirow[t]{2}{*}{$30 \mathrm{~m}$} & Large & 1 & 3 & 0 & 50 & 1 & 10 \\
\hline & Smail & 0 & 0 & 0 & 19 & 0 & 1 \\
\hline${ }^{a}$ See text & & & & & & & \\
\hline
\end{tabular}


they moved to the high ground farthest from the lagoon and built burrows where they passed the winter. Generally, the seasonal change in the densities of large individuals corresponded to that in the densities of large burrows (Fig. 5) in the reed marsh, indicating that
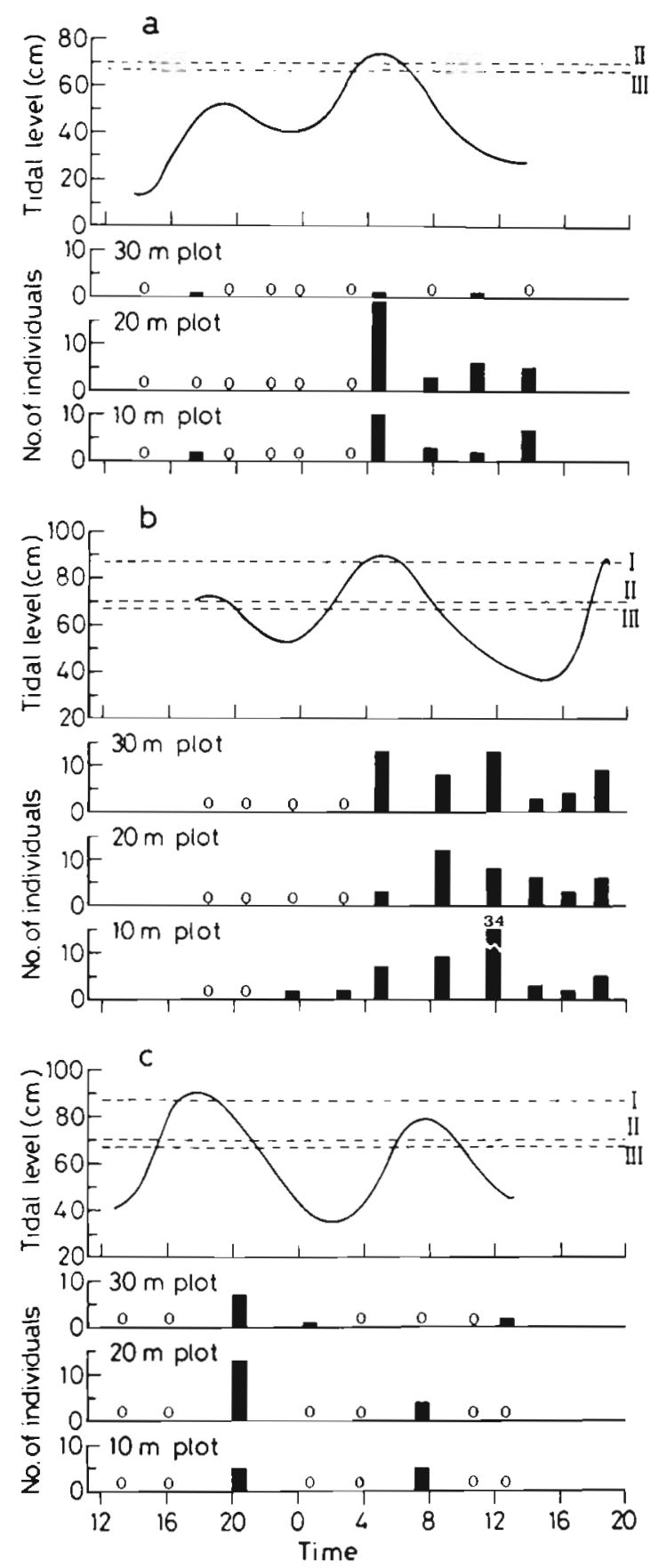

Fig. 4. Helice tridens. Relationship between tidal rhythm and number of large crabs trapped in the square vessels $(25 \times 25$ $\times 37 \mathrm{~cm}$ height projecting $1 \mathrm{~cm}$ above the sediment surface) placed at $30 \mathrm{~m}$ (I), $20 \mathrm{~m}$ (II) and $10 \mathrm{~m}$ (III) stations in the reed marsh on (a) 18 to 19 Jun, (b) 29 to 30 Aug, and (c) 15 to 16 Oct 1985 the decrease in the density of large burrows in the summer was caused by the decrease in the number of large individuals.

\section{Laboratory experiments}

Burrowing behaviour in experimental habitat

Fig. $7 \mathrm{a}$ and $\mathrm{b}$ show the relationship between the number of large and small individuals, respectively, and the numbers of such individuals which burrowed, after transferring summer-collected crabs to the experimental habitats. Most of the large individuals did not build burrows but wandered about on the surface of the sediment (Fig. 7a). Small individuals dug burrows and inhabited them when the population density was less than 16 ind. per $1.56 \mathrm{~m}^{2}$ of 'reed marsh'. When the numbers of individuals per unit area of 'reed marsh' exceeded 16, however, some failed to build burrows, and tended to remain on the surface (Fig. 7b).

In a similar experiment in the fall, an increase in the number of burrows of large individuals was observed in proportion to population density (Fig. 7c). The number of burrows of small individuals also increased with the number of individuals, and was higher than that in the summer (Fig. 7d)

Habitat preference of wandering individuals in experimental habitat

Table 2 shows the sites to which small individuals had migrated during the exposed period in relation to density. All of them inhabited burrows in the 'reed marsh' when they were few in number. When the density of individuals increased beyond 16, some occurred outside burrows but most remained on the 'reed marsh'. Large individuals, however, were observed not to build burrows but to migrate between 'reed marsh' and 'lagoon' repeatedly (Table 3). This result suggests that large individuals have high activity and a wide wandering area and that small individuals showed greater preference for 'reed marsh'.

Relationship between water level and number of wandering crabs in experimental habitat

During the daytime, the number of large individuals on the sediment surface increased with 'flood tide', decreased again during the 'highest tide' and started to increase again with 'ebb tide', and then finally decreased at 'low water' (Fig. 8a). The number of wandering small individuals increased during a transition 


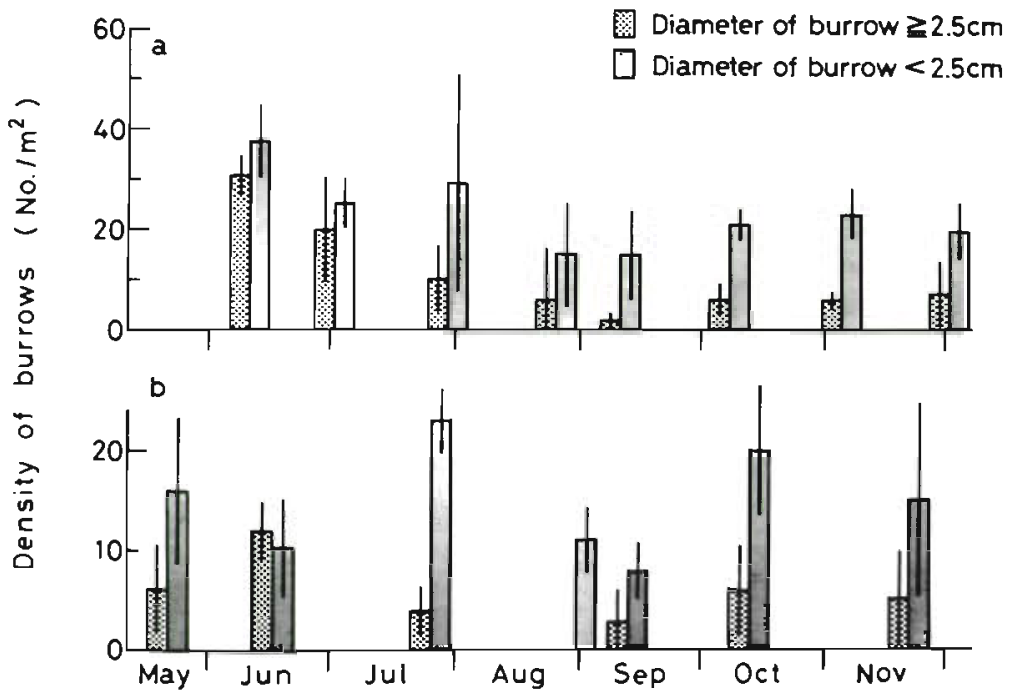

Fig. 5. Helice tridens. Seasonal changes in burrow densities in reed marsh in (a) 1983 and (b) 1984. Each bar shows average values of 4 quadrats (50 $\times 50 \mathrm{~cm}$ ) with $\mathrm{SD}$ period from 'highest tide' to 'lowest tide' and then decreased as 'ebb tide' proceeded (Fig. 8b). At night, large (Fig. 8c) and small individuals (Fig. 8d) showed similar patterns to those of small crabs in the daytime (Fig. 8b), and changes for small individuals during 'ebb tide' were more apparent than those for large crabs. The number of wandering individuals at night was nearly the same as in the daytime, regardless of body size.

\section{Cannibalism in experimental habitat}

In the spring and fall, nearly all of the crabs transferred to the experimental habitat survived (Table 4). But in the summer the survival rate of the small $(1.0$ to $2.0 \mathrm{~cm}$ carapace width) and middle-size $(2.0$ to $2.5 \mathrm{~cm})$

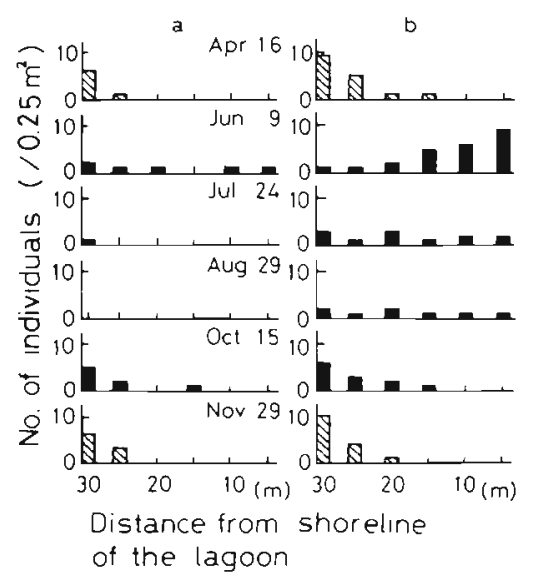

Fig. 6. Helice tridens. Seasonal changes in distribution on the reed marsh. (a) Large individuals $(2.0$ to $3.0 \mathrm{~cm}$ carapace width); (b) small individuals $(<2.0 \mathrm{~cm}$ carapace width). Horizontal axis: distance from the seaward edge of reed marsh; hatched bars: individuals passing the winter in burrows individuals fell to below $50 \%$ at high population density and to $58 \%$ and $67 \%$, respectively, at medium population density. At low density, only small individuals showed decreased survival rate $(50 \%)$. It is thus apparent that, in summer, individuals with a carapace width below $2 \mathrm{~cm}$ were preyed upon by large individuals when population density is rather high, since the remains of half-eaten bodies were often observed.

\section{DISCUSSION}

In summer, many crabs were trapped in the vessels which were partially buried in the reed marsh (Table 1). Takeda \& Kurihara (1987b) have reported that the turnover rate of burrows, i.e. the frequencies of numbers of collapsed and rebuilt burrows, was higher in summer than spring. Each of these observations suggest that there is an increase in the number of burrow-leaving and wandering individuals in the summer. Yamaguchi (1970), considers temperature one of the most important physical factors affecting the activity of such crabs, based on the examination of seasonal changes in the activity of the fiddler crab Uca lactea. Present results also suggest that the increase in wandering Helice tridens in summer is also related to increased locomotor activity associated with increased temperature.

Large individuals wandered as far as the lagoon in front of the reed marsh (Figs. 2 and 3). Hardly any large burrows could be found in the reed marsh during the summer, while small ones were always evident, though the number fluctuated monthly (Fig. 5). These results correspond to the seasonal changes in distribution patterns of large and small crabs in the reed marsh (Fig. 6). It is thus apparent that large crabs move away from the reed marsh. In spring and fall, the number of 
a
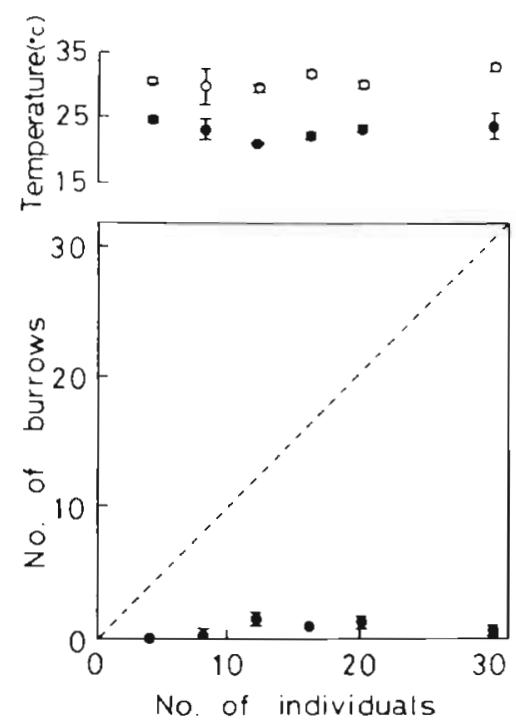

C

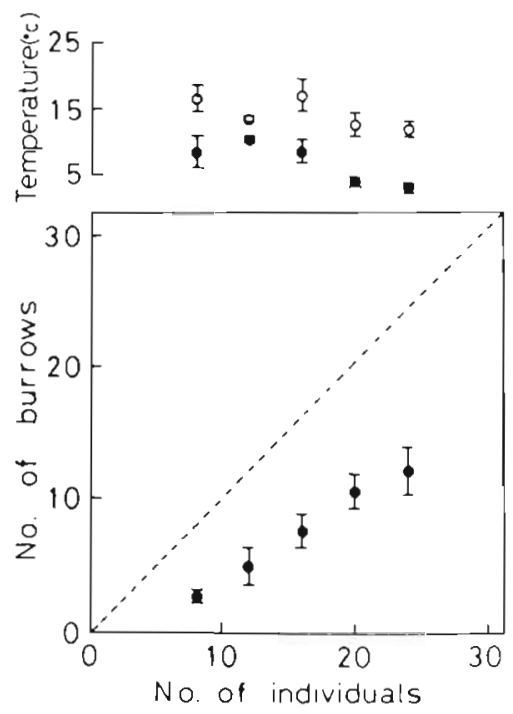

b
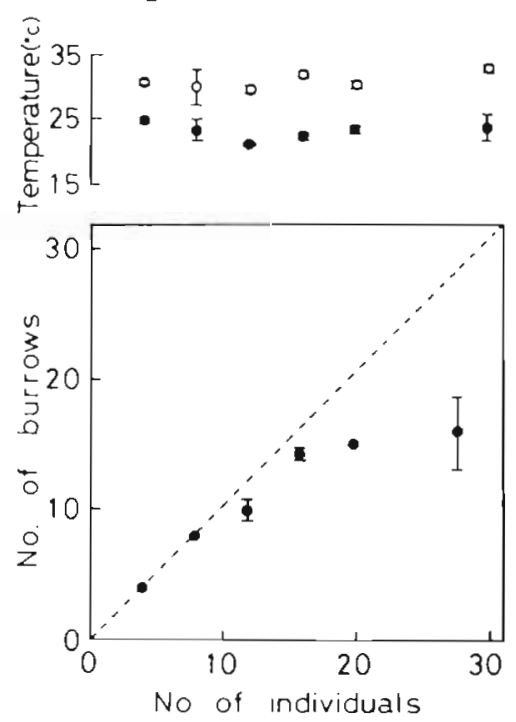

d

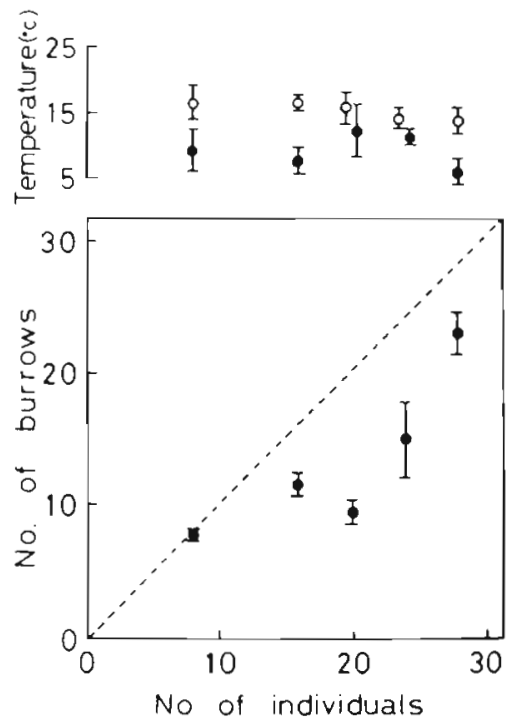

Fig. 7. Helice tridens. Relationship between total and burrowing individuals in experimental habitat. Highest and lowest temperature reported by the Sendai Meteorological Observatory are shown. Burrow number is shown as mean and SD of triplicate observations. (a) Large individuals (carapace width $2.7 \pm 0.11 \mathrm{~cm}$ ), 15 Aug to $12 \mathrm{Sep}_{\text {; }}$ (b) small individuals (1.59 $\pm 0.16 \mathrm{~cm}$ ), $25 \mathrm{Aug}$ to $13 \mathrm{Sep}$; (c) large individuals $(2.74 \pm 0.13 \mathrm{~cm}), 29$ Oct to $20 \mathrm{Nov}$; (d) small individuals $(1.58 \pm 0.10 \mathrm{~cm}), 16$ Oct to $13 \mathrm{Nov} 1985$

Table 2. Helice tridens. Location of small individuals in the experimental habitat in relation to their numbers. Data are shown as means \pm SD of 3 observations. The experiment was performed from 25 Aug to 13 Sept 1985

\begin{tabular}{|ccccc|}
\hline $\begin{array}{c}\text { Total no. } \\
\text { of ind. }\end{array}$ & $\begin{array}{c}\text { No. of ind. } \\
\text { inhabiting burrows }\end{array}$ & 'Reed marsh' & $\begin{array}{c}\text { No. of ind. outside burrows } \\
\text { 'Tidal flat' }\end{array}$ \\
\hline 4 & $4 \pm 0$ & 0 & 0 & 0 \\
8 & $8 \pm 0$ & 0 & 0 & 0 \\
12 & $10.0 \pm 0.8$ & $1 \pm 0$ & 0 & $1.0 \pm 0.8$ \\
16 & $14.3 \pm 0.5$ & $1.3 \pm 0.5$ & 0 & $0.3 \pm 0.5$ \\
20 & $15 \pm 0$ & $4 \pm \pm 0$ & 0 & 1 \\
28 & $16.0 \pm 2.8$ & $10.3 \pm 2.9$ & 0 & $2.0 \pm 1.6$ \\
\hline
\end{tabular}


Table 3. Helice tridens. Location of large individuals in the experimental habitat during 'low tide' at 30 min intervals from 14:00 to $23: 00 \mathrm{~h}$. ' $\mathrm{M}$ ' and ' $\mathrm{F}$ ' refer to locations of male and female, respectively. The experiment was performed on 5 Sep 1985

\begin{tabular}{|c|c|c|c|c|c|}
\hline Time (h) & 'Reed r & narsh' & 'Tidal flat' & \multicolumn{2}{|c|}{ 'Lagoon } \\
\hline $14: 00$ & $M$ & $\mathrm{~F}$ & & & \\
\hline $14 .: 30$ & & & & $M$ & $F$ \\
\hline $15: 00$ & & & & $M$ & $\mathrm{~F}$ \\
\hline $15: 30$ & & $\mathrm{~F}$ & & $M$ & \\
\hline $16: 00$ & & & $M$ & & $\mathrm{~F}$ \\
\hline $16: 30$ & $M$ & & & & $F$ \\
\hline $17: 00$ & & F & & $M$ & \\
\hline $17: 30$ & $M_{1}$ & F & & & \\
\hline $18: 00$ & $M_{1}$ & F & & & \\
\hline $18: 30$ & & F & & $M$ & \\
\hline $19: 00$ & & F & & $M$ & \\
\hline $19: 30$ & $M_{1}$ & $\mathrm{~F}$ & & & \\
\hline $20: 00$ & $M_{i}$ & $\mathrm{~F}$ & & & \\
\hline $20: 30$ & $M_{1}$ & $\mathrm{~F}$ & & & \\
\hline $21: 00$ & & & & $\mathrm{M}_{1}$ & $F$ \\
\hline $21: 30$ & $M_{1}$ & F & & & \\
\hline $22: 00$ & $M_{1}$ & F & & & \\
\hline $22: 30$ & & & $M, \quad F$ & & \\
\hline $23: 00$ & $\mathrm{M}_{1}$ & $F$ & & & \\
\hline
\end{tabular}

individuals trapped in vessels placed on the reed marsh was high when the habitat area in the reed marsh was submerged at flood tide (Figs. $4 \mathrm{a}, \mathrm{c}$ ). This is in agreement with the experimental result in October that the burrow-leaving individuals increased when the reed marsh' was submerged by the 'flood tide' (Fig. 8). In August, however, there is no correlation between tidal level and number of trapped large individuals (Fig. 4b). This may be other evidence of the increase in activity in the summer. This consideration may explain our observations that the wandering large individuals appeared in the lagoon, in which brackish water is always present.
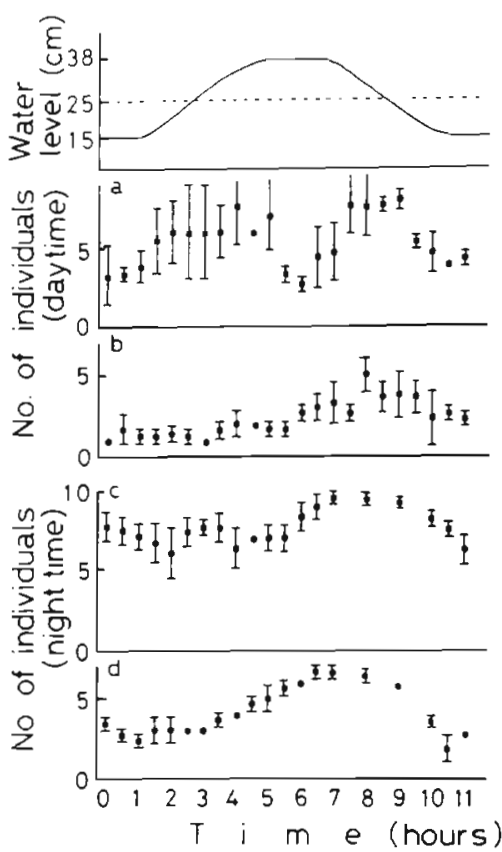

Fig. 8. Helice tridens. Relationships between changes in water level in experimental habitat and number of burrow-leaving large $(a, c)$, and small $(b, d)$ individuals. Data are shown as means and SD of 5 determinations between 26 Sep and 5 Oct 1986. Dashed line corresponds to the height of the border between 'reed marsh' and 'tidal flat'

Some species of ocypodid crab have been reported to migrate to and feed on exposed tidal flats at lower levels than their burrows (e.g. Yamaguchi \& Tanaka 1974, Wada 1981, Murai et al. 1982, Henmi 1984). However, large individuals of Helice tridens were found to wander frequently in the brackish-water lagoon. Ocypodid crabs are considered to feed mainly on fine sediment particles, since they have a cheliped morphologically adapted for effectively handling fine particles (Ono 1965, Wada 1982). However, H. tridens does not possess

Table 4. Helice tridens. Survival rates of small, medium-sized and large individuals transferred to 3 experimental habitats in total numbers of 30, 36 and 48 (see text). Spring: 2 Jun to 4 Jul; Summer: 19 Aug to 15 Sep; Fall: 15 Oct to 15 Nov

\begin{tabular}{|c|c|c|c|c|}
\hline \multirow[t]{2}{*}{ Season } & \multirow{2}{*}{$\begin{array}{c}\text { Density per } \\
\text { vessel }\end{array}$} & \multicolumn{3}{|c|}{ Survival rate $(\%)$} \\
\hline & & $\begin{array}{c}\text { Small } \\
(\text { carapace }=1.61 \mathrm{~cm})\end{array}$ & $\begin{array}{c}\text { Medium } \\
\text { (carapace }=2.27 \mathrm{~cm} \text { ) }\end{array}$ & $\begin{array}{c}\text { Large } \\
\text { (carapace }=2.72 \mathrm{~cm})\end{array}$ \\
\hline \multirow[t]{3}{*}{ Spring } & 30 & 100 & 100 & 100 \\
\hline & 36 & 95.8 & 100 & 100 \\
\hline & 48 & 96.9 & 100 & 100 \\
\hline \multirow{3}{*}{ Summer } & 30 & 50.0 & 100 & 100 \\
\hline & 36 & 58.3 & 66.7 & 100 \\
\hline & 48 & 40.6 & 50.0 & 100 \\
\hline \multirow[t]{3}{*}{ Fall } & 30 & 100 & 100 & 100 \\
\hline & 36 & 100 & 100 & 100 \\
\hline & 48 & 93.8 & 100 & 100 \\
\hline
\end{tabular}


such a cheliped, and thus possibly does not feed only on fine particles in the sediment (Takeda \& Kurihara 1987a). Also, feeding activity of the ocypodid crab has been observed at low tide (e.g. Fielder 1970, Yamaguchi 1970, Evans et al. 1976, Wada 1985). But in the late summer, $H$. tridens feed frequently on seaweed and benthic animals in the brackish-water lagoon (Takeda et al. 1988). These differences in food source may be related to the site of wandering as well as to the physical structure of the cheliped, that is, the tidal flat for ocypodid crabs and lagoon for $H$. tridens. Helice crassa, a congeneric species of $H$. tridens, has been reported to migrate at high tide (Williams et al. 1985), consistent with present observations of $H$. tridens wandering in the lagoon at high tide.

In the experimental habitat, small individuals of Helice tridens dug burrows in 'reed marsh' in the summer (Fig. 7b), and were found to wander in the 'reed marsh' when the population density increased (Table 2). This result indicates that a reed marsh can accommodate a certain number of burrows, this number being less in summer than fall (Figs. 7b, d). The wandering may be caused by interactions among individuals which become severe when population density is high and activity increases in summer, since this species has been reported to show territorial behaviour around its burrows (Ono 1959).

In summer, half or more of the small and middle-size individuals in the experimental habitats disappeared at medium and high population densities (Table 4), and the number of small individuals decreased to nearly the same level of burrow carrying capacity in the experimental habitat (about 16 per unit area) (Fig. 7b). The small wandering individuals may possibly have been consumed by large ones, since in some cases the eaten remains of small individuals were found. From this, it follows that burrows may provide a source of protection for individuals from those that are larger. Burrows also protect the crabs from desiccation and extremely high temperature (Goshima et al. 1978). In addition, no cannibalism was noted in spring and fall (Table 4), possibly due to the lower activity and greater burrow carrying capacities (Figs. 7c, d).

In the experimental habitat, the extent of wandering of small individuals was confined to the reed marsh (Table 2), while large ones were observed to migrate from the reed marsh to lagoon and back again (Table 3). Under natural field conditions, the density of small individuals decreased as they became distributed throughout the reed marsh (Fig. 6). Also large individuals disappeared in the reed marsh in the summer, consistent with our observation that they wander about the lagoon in front of the marsh (Figs. 2 and 3). This wandering under natural field conditions results in their segregation from small individuals, thus lessening the chance of cannibalism. The wandering behaviour may therefore contribute positively to the preservation of this species. Our contention for evasion of cannibalism among Helice tridens supports the contention by Stevens \& Armstrong (1984) that 2-yr or older Dungeness crabs Cancer magister migrate out of the estuary or disperse throughout the estuary, leading to reduced cannibalism.

Acknowledgements. We express cordial thanks to Dr S. Takeda, Faculty of Science of Tohoku University, for his useful discussion, and his help during preparation of the manuscript and for their field assistance. This study was partly supported by the Grant-in-Aid for Special Project Research of the Ministry of Education, Science and Culture, Japan (Nos. $60030005 \& 61030005)$

\section{LITERATURE CITED}

Bulter, T. (1954). Food of the commercial crab in the Queen Charlotte Islands region. Prog. Rep. Pacif. Cst Stns 99: 3-5

Evans, S. M., Cram, A., Eaton, K., Torrance, R., Wood, V. (1976). Foraging and agonistic behaviour in the ghost crab Ocypode kuhlii De Haan. Mar. Behav. Physiol. 4: 121-135

Fielder, D. R. (1970). The feeding behaviour of the sand crab Scopimera inflata (Decapoda, Ocypodidae). J. Zool., Lond. 160: $35-49$

Goshima, S., Izawa, M., Ono, Y. (1978). A preliminary study on the habitats and daily activities of some grapsid crabs and a land crab. Benthos Res. Jpn 15-16: 28-33. (Japanese)

Gotshall, D. W. (1977). Stomach contents of northern California Dungeness crabs, Cancer magister. Calif. Fish Game 63: 43-51

Henmi, Y (1984). The description of wandering behaviour and its occurrence varying in different tidal areas in Macrophthalmus japonicus (De Haan) (Crustacea: Ocypodidae). J. exp. mar. Biol. Ecol. 84: 211-224

Kurihara, Y., Okamoto, K. (1987). Cannibalism in a grapsid crab, Hemigrapsus penicillatus. Mar. Ecol. Prog. Ser. 41: 123-127

MacKay, D. C. G. (1942). The Pacific edible crab, Cancer magister. Bull. Fish. Res. Bd Can. 66: 1-32

Murai, M., Goshima, S., Nakasone, Y. (1982). Some behavioral characteristics related to food supply and soil texture of burrowing habitats observed on Uca vocans vocans and $U$. lactea perplexa. Mar. Biol. 66: 191-197

Ono, Y. (1959). The ecological studies on brachyura in the estuary. Bull. mar. biol. Stn Asamushi, Tohoku Univ. 9: $145-148$

Ono, Y. (1965). On the ecological distribution of ocypodid crabs in the estuary. Mem. Fac. Sci. Kyushu Univ., Ser. E. 4: $1-60$

Stevens, B. G., Armstrong, D. A. (1984). Distribution, abundance, and growth of juvenile Dungeness crabs, Cancer magister, in Grays Harbor Estuary, Washington. Fish. Bull. U.S. 82: $469-483$

Stevens, B. G., Armstrong, D. A., Cusimano, R. (1982). Feeding habits of the Dungeness crab Cancer magister as determined by the index of relative importance. Mar. Biol. 72: $135-145$

Takeda, S., Kurihara, Y. (1987a). The distribution and abundance of Helice tridens (De Haan) burrows and substratum 
conditions in a northeastern Japan salt marsh (Crustacea: Brachyura). J. exp. mar. Biol. Ecol. 107: 9-19

Takeda, S., Kurihara, Y. (1987b). The effects of burrowing of Helice tridens (De Haan) on the soil of a salt marsh habitat. J. exp. mar. Biol. Ecol. 113: 79-89

Takeda, S., Matsumasa, M., Kurihara, Y. (1988). Seasonal changes in the stomach contents of the burrowing mudcrab, Helice tridens (De Haan). Bull. mar. biol. Stn. Asamushi, Tohoku Univ. 18: 77-86

Wada, K. (1981). Wandering in Scopimera globosa (Crustacea: Ocypodidae). Publs Seto mar. biol. Lab. 5: 189-200

Wada, K. (1982). Substratum preference and feeding activity in Scopimera globosa De Haan and Ilyoplax pusillus (De Haan) (Crustacea: Ocypodidae). Benthos Res. Jpn 23: 14-26
Wada, K. (1985). Unique foraging behaviour of Dotillopsis brevitarsis (Crustacea Brachyura: Ocypodidae). J. Ethol. 3: $76-78$

Williams, B. G., Naylor, E., Chatterton, T D. (1985). The activity patterns of New Zealand mud crabs under field and laboratory conditions. J. exp. mar. Biol. Ecol. 89: $269-282$

Yamaguchi, T. (1970). Ecology of a fiddler crab (Uca lactea) (I). Calanus 2: 5-30. (Japanese; English abstract)

Yamaguchi, T., Tanaka, M. (1974). Studies on the ecology of a sand bubbler crab, Scopimera globosa De Haan (Decapoda, Ocypodidae). I. Seasonal variation of population structure. Jap. J. Ecol. 24: 165-174. (Japanese; English synopsis and summary)

This article was submitted to the editor; it was accepted for printing on August 15, 1988 